\title{
A paisagem cultural como novo paradigma para a proteção: a experiência do Vale do Ribeira-SP
}

Flávia Brito do Nascimento*

Simone Scifoni ${ }^{* *}$

\section{Resumo}

Fruto das experiências desenvolvidas pela Unesco desde 1992 e das proposições estabelecidas na Convenção Europeia da Paisagem, o tema das paisagens culturais coloca-se na atualidade como uma forma inovadora de conceber a proteção e a gestão do patrimônio cultural. Em primeiro lugar porque permite superar a dicotomia até hoje presente na atuação dos órgãos públicos de preservação, no que diz respeito ao tratamento entre o patrimônio material e imaterial, entre o natural e o cultural, entendendo-os como um conjunto no qual os seus diferentes significados se articulam num todo vivo e dinâmico. Por outro lado, a forma como têm sido desenvolvidas as primeiras experiências na esfera pública patrimonial em território nacional mostra outra faceta igualmente interessante na atuação em paisagem cultural: a compreensão de que a proteção e a gestão deste patrimônio devem ser feitas com a participação das populações moradoras, por meio do envolvimento e da valorização dos saberes locais. Este artigo procura refletir sobre a aplicação deste novo modelo de proteção do patrimônio cultural que vem sendo desenvolvida no estado de São Paulo pelo Instituto do Patrimônio Histórico e Artístico Nacional (Iphan), na região do Vale do Ribeira de Iguape, buscando mostrar o caminho teórico-metodológico adotado no estudo e de que forma foram sendo construídas a pesquisa científica e nova forma de atuação e inserção local.

Palavras-chave: Paisagem cultural. Patrimônio cultural. Vale do Ribeira, SP, Brasil.

\section{Cultural landscapes as a new preservation paradigma: the Ribeira Valley (SP) experience}

\section{Abstract}


As argued by Unesco since 1992 and by the Europeean Convention, cultural landscapes is, nowadays, a new way of dealing with cultural heritage and its management. First of all, because it aims overcoming the false dichotomy between material and immaterial heritage frequently existent in public policies, and by understanding natural and cultural as unites, vividly articulated. In other hand, to protect and manage the areas with cultural landscapes concepts is necessary evolves considering local knowledge. This paper aims discussing the application of cultural heritage concepts in the State of São Paulo, particularly in the Ribeira Valley, presenting theoretical and methodological concepts paths.

Key-words: Cultural landscapes. Cultural heritage. Ribeira Valley, SP, Brazil.

\section{Paisagem cultural: conceituação e método}

Há uma longa discussão sobre o conceito de paisagem cultural, oriunda, de um lado, da produção acadêmica, sobretudo na ciência geográfica, e, por outro lado, da experiência internacional a partir dos trabalhos da Unesco e da Convenção Europeia da Paisagem (RIBEIRO, 2007). Estes trabalhos somam-se a iniciativas mais recentes levadas a termo pelo Iphan, de elaboração de normatizações visando traçar uma linha de atuação no interior das políticas públicas para o patrimônio. Para explicitar os caminhos teóricos adotados no estudo sobre a paisagem cultural do Vale do Ribeira alguns elementos essenciais desta discussão serão aqui apresentados.

Apesar da proteção da paisagem no Brasil estar prevista, desde a edição do decreto-lei federal $n^{\circ} 25$, de 1937, no âmbito do Iphan (1) a renovação das práticas possibilitou colocar a paisagem cultural como novo mecanismo de proteção do patrimônio, a partir da regulamentação estabelecida pela recente Portaria $n^{\circ} 127$, de 30/04/2009 (2).

Ao optarmos pelo Vale do Ribeira como uma área de pesquisa e atuação profissional no âmbito do Instituto do Patrimônio Histórico e Artístico Nacional o enfoque da paisagem cultural mostrou-se o mais pertinente para tratar as questões do patrimônio cultural na região, já que possibilitou um olhar a partir do território 
pressupondo o reconhecimento das relações singulares entre os grupos sociais e a natureza.

Os documentos produzidos pelo Iphan que regulamentam e orientam as ações no que diz respeito à Paisagem Cultural (3), conceituam-na como uma porção do território com características peculiares, produto de relações que os grupos sociais estabelecem com a natureza, relações essas que podem aparecer fisicamente, sob a forma de marcas, e/ou por meio de valores que lhe são atribuídos socialmente. $O$ caráter peculiar ou especial, próprio de algum lugar, é o elemento essencial que faz com que uma determinada paisagem possa ser reconhecida como de importância cultural e, portanto, passível de mecanismos públicos de proteção. O peculiar é, assim, o que dá uma identidade, capaz de diferenciá-la num contexto espacial mais amplo. O que the confere uma dada identidade pode ser, em um primeiro plano, resultado de marcas inscritas no espaço ou de formas reconhecíveis e delimitáveis, as quais compõem uma unidade orgânica (RIBEIRO, 2007).

No que diz respeito a essa morfologia da paisagem, as marcas inscritas aparecem como produto de diferentes momentos históricos que se cristalizam no espaço geográfico, são formas-objeto ou rugosidades (SANTOS, 1978, 2004). Para esse autor, as rugosidades nos permitem entender combinações particulares do trabalho, da técnica e do capital. São testemunhos de um momento do modo de produção e de um momento do mundo, pois a "paisagem é o resultado de uma acumulação de tempos" (SANTOS, 2004, p. 54). Estas formas-objeto são, segundo o autor, tempo passado cristalizado no espaço, mas são, também, tempo presente, pois abrigam uma nova essência ao participar da vida atual como formas indispensáveis à reprodução social.

Considerando os aspectos relativos à morfologia da paisagem, cabe destacar que as marcas traduzem diferentes temporalidades, não somente o tempo da história humana, mas também, o tempo da natureza. A paisagem é sempre uma herança, de um lado de processos naturais milenares e, de outro, herança do trabalho humano que produziu diferentes formas de apropriação social da natureza (AB'SÁBER, 2003). Herança de processos naturais que apresentam uma outra temporalidade, pois são fruto de dinâmicas de longa duração que modelaram o relevo, definiram os 
caminhos preferenciais para as águas dos rios, formaram camadas de solo e determinaram a evolução dos quadros biológicos, constituindo uma base material, a matéria-prima para a ação cultural. "[...] um patrimônio coletivo dos povos que historicamente as herdaram como território de atuação de suas comunidades" (op.cit., p.9).

A paisagem traz, portanto, a marca das diferentes temporalidades desta relação sociedade-natureza, aparecendo, assim, como produto de uma construção que é social e histórica e que se dá a partir de um suporte material, a natureza. A natureza é matéria-prima a partir da qual as sociedades produzem a sua realidade imediata, através de acréscimos e transformações a essa base material. A paisagem como produto do trabalho humano não significa a eliminação dos traços da natureza, os quais se encontram sempre ali presentes, embora, algumas vezes, imperceptíveis.

Nesse sentido, a perspectiva da paisagem cultural implica em que se identifique as relações estabelecidas, nos vários momentos históricos, entre as comunidades locais e a natureza, considerada matéria-prima para a apropriação social. Estas relações entre comunidade-natureza explicam como se deu a produção dos objetos materiais (cidades, edificações, campos de cultivo) e da vida imaterial (festividades, lendas, tradições, crenças, elementos simbólicos, memória coletiva).

Em um segundo plano de análise, é possível afirmar que a "identidade da paisagem" pode ser dada não somente pela forma, mas também pela maneira como as populações a apreendem, ou seja, pela ideia de pertencimento, conforme estabelece a Convenção Europeia de Paisagem (4). Outra vertente de discussão no pensamento acadêmico entende que a paisagem não é somente o visível, ela incorpora valores humanos e pode ser interpretada a partir de seu conteúdo simbólico ou da relação íntima e afetiva que os grupos sociais estabelecem com os lugares onde a vida humana se reproduz (RIBEIRO, 2007). Neste plano, o que dá identificação a uma determinada paisagem pode não corresponder somente à unidade orgânica das formas, mas também o significado de fazer parte daquele lugar. 
É importante lembrar, ainda, que a paisagem não é simples adição ou somatória de elementos ou formas, ela é antes, resultado de uma combinação dinâmica, um sistema de relações que são naturais ou ecológicas e humanas (sociais, políticas e econômicas), que mantêm articulados vários pontos e lugares em um território (BERTRAND, 1972, 1978).

Segundo esse autor, estudar a paisagem é, antes de tudo, um problema de método que envolve pensar de forma integrada as seguintes questões:

- noção de escala: como definir o recorte territorial da paisagem a partir da sua unidade orgânica? Isso implica em fenômenos de escala local ou regional? Como definir a escala do processo?

- a cartografia da paisagem deve partir da compreensão de que toda delimitação é arbitrária se considerarmos o caráter fluido e descontínuo dos fenômenos. A cartografia da paisagem coloca a necessidade de generalizações e de busca dos processos dominantes e/ou hegemônicos e de suas rupturas;

- questões que envolvem a classificação ou a taxonomia da paisagem: implica em pensar o processo-chave que define uma dinâmica em comum, que dá a unidade orgânica, uma combinação local e única de fatores. No entanto é preciso considerar que há especificidades internas que definem subunidades menores, porém articuladas ao todo por relações espaciais e temporais.

Segundo critérios da Unesco (5), a delimitação da paisagem cultural deve levar em conta, ainda, o fato de que a extensão e o limite devem garantir a sua funcionalidade e inteligibilidade. Nesse sentido, a delimitação da paisagem não precisaria necessariamente abarcar a totalidade, podendo constituir-se a partir de um recorte do todo que seja ilustrativo e representativo das qualidades e caráter do conjunto.

\section{Vale do Ribeira e a Paisagem Cultural}

O Vale do Ribeira corresponde a um conjunto de terras banhadas por rios da bacia hidrográfica do Rio Ribeira de Iguape, que compreende 23 municípios localizados no estado de São Paulo, além de outros no Paraná. (6) Trata-se de uma paisagem singular que reúne a um mesmo tempo e, de maneira articulada, várias dimensões do chamado patrimônio cultural: edificações, bens naturais, manifestações culturais imateriais e sítios arqueológicos. 
Por entre os últimos remanescentes de florestas nativas biodiversas que recobrem a topografia acidentada da Serra do Mar e a maior planície sedimentar litorânea paulista (a baixada do Ribeira), nasceram e floresceram núcleos urbanos ligados aos primórdios da exploração colonial do ouro ou à monocultura comercial de arroz do Brasil Império, como as cidades de Iguape, Iporanga e Cananeia. Formaram-se ali, também, núcleos de colonização estrangeira que testemunham as primeiras experiências de imigração japonesa no Brasil, cujos vestígios materiais encontramse, ainda hoje, dispersos em área rural dos municípios de Iguape e Registro.

A natureza forneceu os recursos necessários à produção da vida material: seja o ouro de lavagem somente encontrado serra acima, em terrenos cristalinos e junto às nascentes do Rio Ribeira de Iguape; as terras planas e encharcadas, ambiente propício para a monocultura do arroz; e o próprio Rio Ribeira de Iguape, principal avenida fluvial por onde circulava toda a vida material e social da região. Sendo assim, a construção das cidades e o seu patrimônio edificado testemunham a relação histórica de apropriação humana das condições naturais presentes.

A formação da diversidade cultural existente na região guarda, também, uma ligação estreita com a natureza. Os modos de vida e as manifestações culturais dos diferentes grupos sejam eles ribeirinhos, quilombolas, caiçaras, colonos estrangeiros, comunidades rurais ou urbanas, aparecem como o resultado da forma como eles aprenderam a se relacionar com os recursos naturais existentes, provedores da vida: da cerâmica e cestaria típica, às celebrações que têm no rio o principal protagonista como o Tooro Nagashi, em Registro, quando são jogados no Rio Ribeira réplicas de barcos iluminados em memória das almas dos afogados, ou a Festa de Nossa Senhora do Livramento, em Iporanga, uma procissão aquática que segue o rio. A natureza marca, ainda, o cotidiano das comunidades ribeirinhas e caiçaras que tem nas águas o seu principal meio de vida e circulação: o tempo da lua, das chuvas, das marés.

A paisagem cultural do Vale do Ribeira representa, assim, a íntima relação estabelecida entre os vários grupos sociais ali presentes com a natureza, relação que explica como se deu a produção dos objetos materiais e da vida imaterial. O fio 
condutor para a compreensão das relações entre comunidades e natureza é o próprio Rio Ribeira do Iguape por seu importante papel na construção da identidade e da história regional: vincula-se à trajetória da ocupação do território paulista, tendo servido de elemento aglutinador das cidades, eixo de ligação entre o litoral e o planalto, principal via de comunicação e fonte de recursos para a economia regional.

Seja com a exploração aurífera no período colonial ou a agricultura comercial do arroz no Brasil Império, o Rio Ribeira viabilizou não somente a exportação de produtos e a circulação de mercadorias, como também transportou pessoas, sonhos, esperanças de uma vida melhor, difundiu notícias, hábitos e manifestações culturais. Uma vida social estreitamente ligada ao rio e às possibilidades conferidas pela navegação fluvial, que marcaram festividades, celebrações, imprimiram significados simbólicos para determinados pontos que se tornaram referências: a barra de alguns rios, os encontros das águas, os portos fluviais, os lugares de naufrágio de antigos vapores ou a cachoeira temida pelos canoeiros.

O estudo parte, assim, da ideia do Rio Ribeira de Iguape como elemento de mediação na construção da identidade, da cultura e da história regional. Uma relação que é (re)significada no tempo, ultrapassando o sentido inicial de meio de vida, de transporte e comunicação para tornar-se, contemporaneamente, o elemento entorno do qual se funda a memória coletiva regional. O Ribeira de Iguape constitui uma espécie de corredor cultural, onde transitaram e intercambiaram-se mercadorias, objetos e valores materiais, mas também, modos de vida, tradições, técnicas, conhecimentos, informações. Um corredor que conectou fluxos imateriais e materiais indispensáveis à produção social.

\section{A paisagem como acumulação desigual de tempos}

Muito antes da chegada do colonizador europeu vivia na região uma população de canoeiros, cuja base da alimentação era a pesca e coleta de mariscos, sendo o rio a ligação entre os grupos do planalto e do litoral. Trata-se, assim, de um primeiro momento na compreensão histórica da paisagem que tem seu registro marcado na grande quantidade de sítios arqueológicos encontrados na região e que testemunham a sequência de ocupações pré-históricas, estudadas desde o início do século passado em trabalhos pioneiros (KRONE, 1914). 
Os sítios arqueológicos revelam uma complexidade de situações ainda não totalmente desvendadas e com lacunas do ponto de vista cronológico: sambaquis costeiros com uma grande quantidade de sepultamentos que sugerem uma densidade demográfica considerável e uma complexidade social muito superior ao anteriormente imaginado; sambaquis fluviais mais antigos que os costeiros e com semelhante indústria lítica, predominantemente polida e que problematizam questões sobre a relação entre os povos da costa e do interior; sítios arqueológicos da Tradição Umbu, relativo a grupos de caçadores-coletores com práticas incipientes de agricultura e com material lítico de grande apuro técnico como a "ponta de flecha"; sítios cerâmicos da Tradição Itararé, grupo que já praticava a agricultura.

As heranças deixadas por estas populações resultaram em um potencial arqueológico extremamente elevado, mas que sofreu grandes perdas desde o início da colonização por servirem de fonte de exploração de cal para as construções. São evidências de uma ocupação pretérita que deixou traços tênues na paisagem que o europeu conheceu a sua chegada.

O segundo momento na história da paisagem do Vale aparece com a mineração ocupando, desde o início do século 16, o papel de principal atividade econômica. A descoberta de ouro nas Serras de Paranapiacaba e do Cadeado (Cananeia), incentivou um intenso processo de ocupação do interior, determinando posição de destaque à região na economia colonial. As incursões para o sertão aumentaram, tendo como principal via o rio Ribeira, que estabeleceu uma ponte entre as cidades do alto da serra, onde se encontrava o ouro de aluvião, e os portos no litoral, por onde este era exportado. Surgiram, deste modo, sob a influência do chamado ciclo paulista do ouro, os povoados de Iporanga, Apiaí, Registro e Eldorado, formados a partir de antigos arraiais de garimpo. Ao longo do percurso pelo Rio Ribeira de Iguape, por onde canoas transportavam o ouro de aluvião, instalaram-se portos fluviais, como os de Registro e Porto da Ribeira, em Iguape, que escoavam a produção que vinha serra acima, recolhendo os impostos à Coroa Portuguesa. Ligados estrategicamente ao rio Ribeira, via de ligação natural, encontravam-se 
estradas de terra de caráter complementar, que respondiam pelo trânsito de tropas de muares.

Fatores como a condição abrigada das intempéries costeiras e a presença de águas calmas no Mar Pequeno incentivaram a instalação dos portos marítimos de Cananeia e Iguape e, consequentemente, o crescimento destas vilas. Heranças deste momento encontram-se materializadas na paisagem dessas cidades, seja no traçado das ruas, quarteirões e praças que remetem ao urbanismo colonial português, nos antigos portos que reaparecem após as escavações arqueológicas, ou no casario que permanece.

O esgotamento das jazidas auríferas na região proporcionou uma fase de decadência, superada, no início do século 19, pela monocultura comercial do arroz que tomou grandes proporções e reascendeu a importância das terras cortadas pelo Ribeira, constituindo terceiro momento da constituição da paisagem.

A febre do arroz deu-se ao longo do século 19 quando a produção para exportação atingiu seus valores máximos, colocando Iguape na liderança da economia regional. Exigiu a modernização do sistema de navegação marítimo e fluvial: novos cais de pedra nos portos, embarcações a vapor e a grande obra que acabou por selar o futuro de Iguape: a abertura de um canal artificial ligando o antigo Porto Fluvial da Ribeira ao Mar Pequeno, o chamado Valo Grande. O objetivo era reduzir o tempo gasto no transporte do arroz até o porto marítimo, no entanto, o solapamento constante das margens foi responsável pelo assoreamento do Mar Pequeno, interferindo nas condições portuárias de Iguape e gerando a sua decadência.

No auge da monocultura do arroz, à base do trabalho escravo, demandou-se na região crescente ampliação da mão-de-obra e, mais tarde, a formação de quilombos, a partir da decadência do cultivo, em fins deste mesmo século. As ruínas das fazendas distribuídas na extensa zona rural desta vasta região, o casario urbano dos núcleos de Iguape, Iporanga e Cananeia, o Canal do Valo Grande, a população quilombola e seu modo de vida são alguns dos testemunhos presentes na paisagem deste momento de riqueza e auge, mas também do papel da região na economia do Brasil Império. 
No início do século 20, políticas oficiais de ocupação do território promoveram no Vale do Ribeira as primeiras iniciativas de implantação de núcleos de colonização japonesa no país. As áreas drenadas do Rio Ribeira de Iguape foram fundamentais aos empreendimentos de colonização imigrante, como os da empresa KKKK que cultivou produtos com estreita ligação cultural como o arroz, chá e junco, também escoados pelo Porto ao longo do Ribeira, configurando, desta maneira, mais um momento na história desta paisagem cultural. Ainda hoje estão presentes, dispersos na zona rural de Registro e Iguape, vários remanescentes da arquitetura destes colonos. São casas de moradia, fábricas de chá, igrejas e armazéns para processamento de arroz que evidenciam o contato do imigrante com as condições da nova terra e o processo de (re)significação dos universos. Estas construções associam a técnica e a estética próprias da cultura oriental com as adaptações necessárias ao ambiente tropical.

Mas as marcas desta imigração ainda estão presentes na paisagem nos campos de cultivo do chá e junco, dois produtos trazidos pelos imigrantes e que foram fundamentais à reprodução social do grupo. $O$ chá conforma uma paisagem única e típica em Registro (PETRONE, 1966). Os chazais foram plantados nos terrenos das colinas suaves, ficando, deste modo, ao abrigo das cheias dos rios. Em geral o chá é plantado seguindo as curvas de nível, garantindo proteção ao solo, já que com o seu crescimento, as mudas se unem formando uma cobertura arbustiva densa, fechada e homogênea. A beleza da paisagem do chá em Registro é produto deste conjunto de fatores: de um lado, o sítio físico propício e, de outro, a forma como as lavouras foram dispostas.

Já o junco ocupa os vales de fundo plano que separam as colinas. Sua textura e altura também uniformes formam uma espécie de tapete verde nos fundos de vale encharcados. Ambos os produtos foram trazidos por imigrantes japoneses que poderiam ter se tornado os únicos produtores em toda a região, monopolizando a oferta. No entanto optaram por distribuir mudas entre seus conterrâneos, tornando a região a maior produtora nacional destes tipos de produtos. Ao se disseminar as plantas entre outros agricultores japoneses da região, as mudas tornaram-se símbolo do espírito de cooperação e do sentido coletivo que envolvia cotidianamente 
a vida daqueles imigrantes japoneses, assentados sob o domínio da tropicalidade no sudeste brasileiro e marcaram definitivamente a paisagem cultural do vale.

O momento mais recente da paisagem se constituiu a partir de meados de 1950, quando a região passou por um processo de estagnação econômica, não conseguindo competir com as demais regiões do Estado pela diferença de suas condições. Em geral pelo seu caráter de imensa área rural, marcada por uma agricultura de pequenos proprietários, com produção de alimentos para mercado interno, ausente de iniciativas de industrialização, ao contrário do que ocorria com o restante do estado. Começou a se configurar a ideia de uma região "à margem do império do café", à parte do processo de desenvolvimento rural e urbano que estava se dando no estado de São Paulo (PETRONE, 1966). Nem mesmo o cultivo da banana, que se tornou o carro-chefe da economia da região, foi suficiente para reverter essa condição, a qual, por outro lado, resultou na conservação de grande extensão de vegetação nativa remanescente.

Essa paisagem encantou o escritor Albert Camus, quando esteve em viagem pelo Brasil, em 1949. Convidado para conhecer a festa do Bom Jesus de Iguape, percorreu a região, juntamente com Oswald de Andrade e uma comitiva, em agosto daquele ano ele, relatando em Diário de Viagem a seguinte impressão:

\footnotetext{
Saímos finalmente, para o ar livre e chegamos a uma cidadezinha, onde um grande rio nos obriga a parar. Sinais luminosos na outra margem, e vemos chegar uma grande barcaça, do mais antigo sistema possível, movida por meio de um cabo estendido entre as duas margens do rio e conduzida por mulatos de chapéu de palha. Embarcamos, e a barcaça deriva lentamente sobre o rio Ribeira. O rio é largo e corre suavemente em direção ao mar e à noite. Nas duas margens, uma floresta ainda densa. No céu úmido, estrelas brumosas. Calam-se todos a bordo. O silêncio absoluto deste momento só é perturbado pela batida da água do rio na barcaça. À frente, olho o rio descer, a estranheza, no entanto familiar, deste cenário. (CAMUS, 2004, p. 102).
}

A presença desta vegetação remanescente resultou, principalmente a partir dos anos 1980, na criação de inúmeras áreas naturais protegidas e pela definição de um novo papel da região no conjunto do estado: o de conservação da biodiversidade, marcando contemporaneamente um momento da paisagem cultural. Neste novo 
cenário, o Rio Ribeira deixa de ser somente meio de vida e de transporte, para reforçar seu papel de esteio da memória coletiva da região, o que pode ser evidenciado na histórica luta da sociedade civil em torno de sua preservação frente aos projetos de construção de barragens para aproveitamento hidrelétrico.

\section{A construção da proposta para proteção da Paisagem Cultural}

Do ponto de vista metodológico, inicialmente foram realizadas uma série de levantamentos de campo que permitiram o conhecimento do rico potencial patrimonial do Vale do Ribeira de Iguape acima descrito. Em paralelo foram travados contatos com entidades e instituições locais, de modo a conhecer as expectativas e demandas na área do patrimônio cultural, bem como os projetos em andamento. Tais ações foram feitas tendo vista as diretrizes da Chancela da Paisagem Cultural, que segundo 0 artigo $3^{\circ}$ da Portaria $n^{\circ} 127$, parte do reconhecimento do caráter dinâmico da cultura e de uma realidade que convive com transformações, não cabendo, portanto, a ideia de congelamento no tempo. Quando se trata da proteção da paisagem, essas transformações devem compatibilizar-se com formas de desenvolvimento social e econômico sustentáveis, de maneira a garantir a preservação e valorização do patrimônio cultural.

Para proporcionar a eficácia na proteção desse patrimônio cultural, levando-se em conta a sua dimensão como recorte do território, a chancela da paisagem cultural demanda o estabelecimento de um pacto a ser firmado entre o poder público e a sociedade. O pacto constitui-se a partir de um processo de envolvimento e de interlocução nas localidades, junto àqueles parceiros preferenciais interessados em sua concretização, buscando a formulação de uma proposta de proteção.

Visando a construção deste pacto, de 2007 a 2009 foram feitos contatos, conversas e reuniões técnicas com diversas instituições governamentais atuantes no Vale do Ribeira em âmbito federal, estadual e municipal, com as organizações nãogovernamentais, movimentos sociais, associações de moradores, sindicatos, cooperativas, universidades, entre outros setores. Dentre estas ações que buscaram a interlocução local destacam-se: a realização de um encontro de trabalho para discussão de um planejamento estratégico conjunto para a proteção do patrimônio, envolvendo as diversas esferas; oficinas de educação patrimonial objetivando a 
participação social na identificação dos patrimônios a serem protegidos com respectiva produção de material a partir deste olhar local; organização e abertura de uma Casa do Patrimônio em Iguape pela Superintendência Regional do Iphan em São Paulo em parceria com a Prefeitura Municipal de Iguape, como um espaço de diálogo constante com as comunidades e de fomento à pesquisa e à reflexão sobre a temática; reuniões com movimento social para elaboração conjunta de uma proposta de proteção. Destas discussões foi definido um conjunto de critérios para delimitação da paisagem cultural do Vale do Ribeira de Iguape na sua porção paulista e proteção dessa paisagem cultural, os quais são apresentados a seguir. (Figura 1)

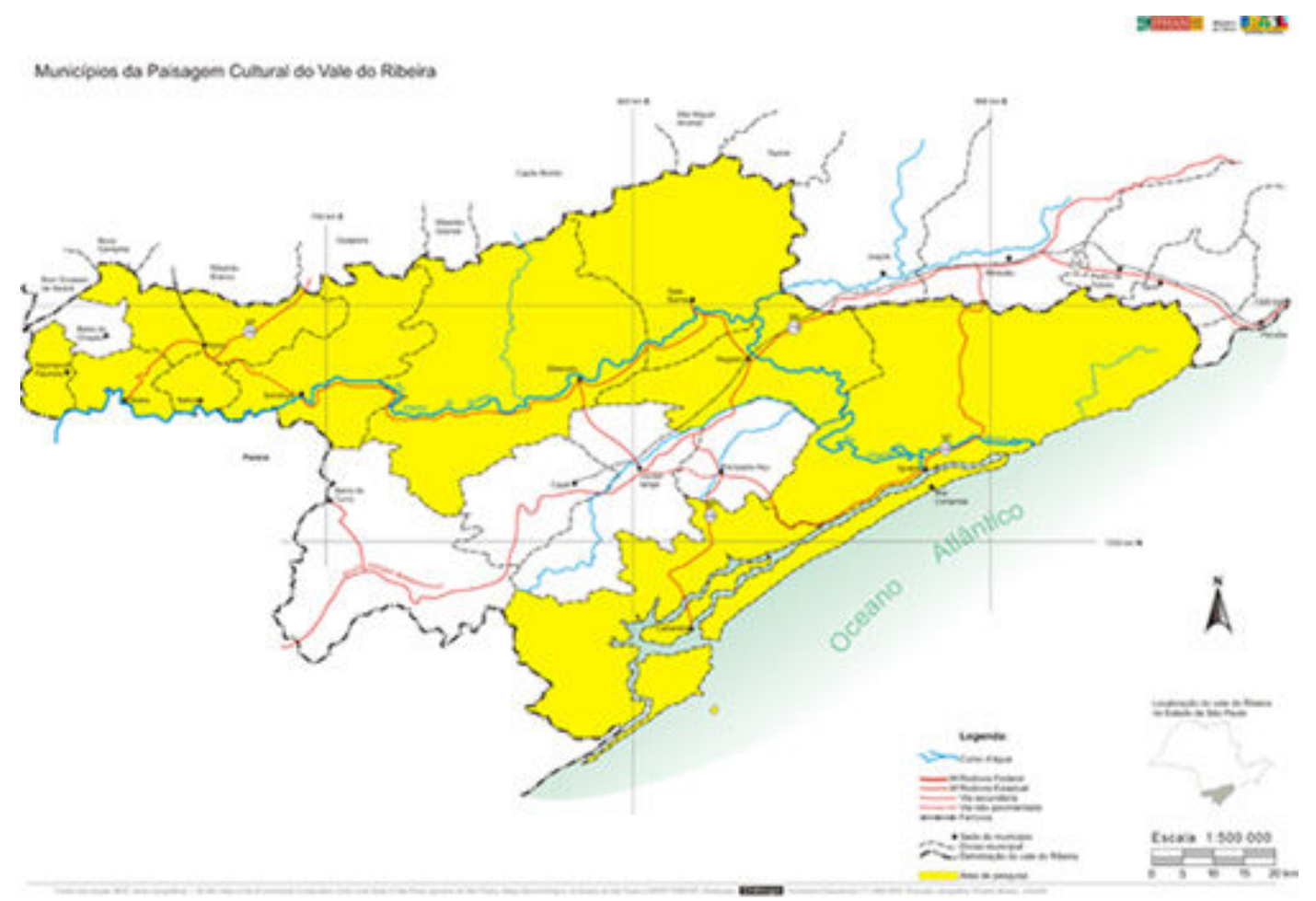

Figura 01 - Municípios que integram a paisagem cultural do Vale do Ribeira de Iguape-SP

Como critério essencial para a definição dos limites da paisagem adotou-se o princípio de que a parte pode representar o todo, ou seja, de que não necessariamente é preciso incluir um vasto território entendido como a totalidade dos processos, sendo que um recorte deste espaço pode ilustrar as relações históricas estabelecidas pelos grupos sociais na apropriação da natureza. Tal critério baseia-se fundamentalmente na preocupação em garantir uma operacionalidade 
para a gestão do território protegido, cuja extensão pode, por vezes, comprometer o objetivo maior da proteção do patrimônio.

Além disso, ressalta-se o fato de que, a região foi objeto, ao longo dos anos, de instituição de uma diversidade de categorias de áreas naturais protegidas, federais, estaduais e inclusive, internacionais, que já garantem atribuição de valor à natureza e, portanto, proteção legal. O que ficou fora desta proteção foi justamente o que é agora objeto da abordagem da paisagem cultural, ou seja, aquilo tudo que ilustra a relação histórica entre sociedade e natureza. Portanto, há de se observar que a proposta de perímetro abrange em parte, algumas áreas já protegidas e, em parte, outras que ainda não o são.

Neste caso, o recorte não é a somatória de elementos, mas ao contrário, ele busca ilustrar e representar a riqueza e a diversidade do todo a partir das relações estabelecidas entre as partes. O recorte buscou garantir, também, a funcionalidade, a inteligibilidade e a possibilidade de leitura articulada do todo. Neste sentido, as conexões se fazem a partir do eixo central da abordagem da paisagem cultural, ou seja, pelo Rio Ribeira de Iguape.

Compreende-se a paisagem cultural não como uma somatória de objetos, lugares ou pontos do espaço, mas como um sistema de relações que mantêm conectados os lugares do território a partir de aspectos que são estéticos, históricos, espaciais, simbólicos, funcionais e ambientais (RIBEIRO, 2007). As relações permitem entender a paisagem como um todo orgânico que deve ser gerenciado, portanto, como uma unidade.

Adotando-se o critério do Rio Ribeira de Iguape como o elemento de conexão, a delimitação do perímetro seguiu a ideia de uma paisagem linear ou paisagemcorredor, como expressão de uma rede cultural tecida, historicamente, ao longo de um eixo principal de comunicação e transporte. (Figura 2) 


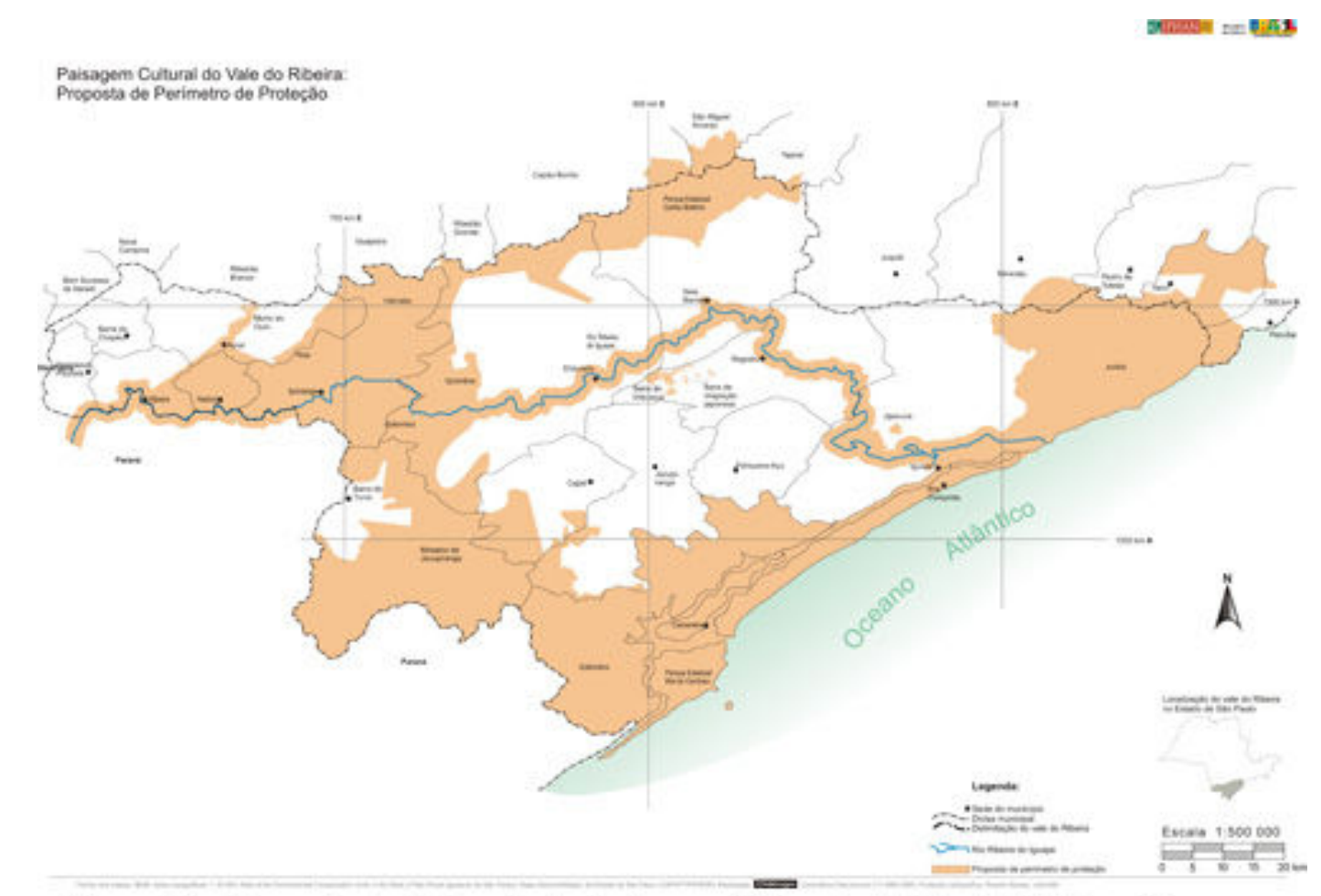

Figura 02 - Proposta de Proteçăo da Paisagem Cultural do Vale do Ribeira-SP.

Neste sentido o limite da paisagem cultural inicia no ponto de entrada do Rio Ribeira em território paulista (já que as nascentes são no Estado do Paraná) e termina junto a sua foz, no oceano, acompanhando uma faixa de dois quilômetros de cada lado da margem. A definição desta faixa procurou incorporar as cumeadas dos morros e serras que delimitam as vertentes que formam a feição do vale, propriamente dito, que conformam o que se pode dizer de uma paisagem fluvial. Nos seus trechos em que a planície se abre e forma-se uma várzea ampla e baixa, não havendo encostas próximas a definir o vale, o limite de dois quilômetros buscou incluir aquelas feições articuladas a sua dinâmica milenar e que contam a sua história, ou seja, as lagoas marginais e antigos meandros do rio. Além disso, tendo em vista a funcionalidade, inteligibilidade e a possibilidade de leitura articulada da paisagem, sugeriu-se ampliar a faixa de proteção dos dois quilômetros para os trechos de margem do Rio Ribeira de Iguape que se encontram no Estado do Paraná, prevendo-se ações de articulação com as duas Superintendências dos estados.

Buscou-se com a identificação desta área, preservar a paisagem fluvial de meandros encaixados e suas vertentes limítrofes, além dos trechos de várzea com suas lagoas marginais e as barras dos principais afluentes, associado ao rico potencial 
arqueológico existente. Além do relevante valor paisagístico, tais áreas são suporte físico necessário à proteção e continuidade de uma diversidade de cultura imaterial e são locais de relevante valor para a memória regional (portos e pontos de ancoradouros, barras de rios, locais de travessia por balsas, entroncamentos, entre outros).

Nesta faixa de dois quilômetros, algumas cidades foram incluídas no perímetro da paisagem cultural como assentamentos urbanos singulares e únicos, caso de Ribeira e Iporanga. Outras duas cidades, Eldorado e Registro, situadas à margem do rio, também fazem parte da paisagem cultural. O objetivo é garantir a relação das cidades e de sua gente com seu rio e a proteção do curso e sua faixa marginal.

Como os significados dos pontos dessa rede cultural são dados pelos intercâmbios e pela dinâmica do movimento ao longo da história, a este segmento linear ao longo do rio foram conectando-se a outros lugares representativos do processo. Seguindo o rio em direção à jusante foram incluídas as estradas que constituíram antigos caminhos de tropa, de caráter complementar, que ligavam o Rio Ribeira até as minas de ouro de Apiaí (estradas de Ribeira, Itaoca e Iporanga).

Em continuidade com as terras cortadas pelas estradas, incluem-se no perímetro da paisagem cultural os parques estaduais como Petar, Intervales e Carlos Botelho e o Mosaico de Jacupiranga, assim como o Parque Natural Municipal do Morro do Ouro. Além das características naturais, a seleção destes parques leva em conta o fato de que estas unidades abrigam sítios arqueológicos históricos e pré-históricos, ruínas e vestígios materiais relacionadas quer ao garimpo de ouro dos primórdios da ocupação no Vale do Ribeira ou da mineração de chumbo do início do século 20 .

Aos parques estaduais conectam-se os territórios quilombolas, levando-se em consideração que muitas das terras reconhecidas como tal estão sobrepostas a unidades de conservação. Estas terras testemunham modos de vida e modalidades de uso do solo que são herança de séculos de relação entre estes grupos sociais e a natureza, considerada como base material para a reprodução da vida humana e são o locus onde se desenvolve uma cultura imaterial rica e diversificada. Como o Vale do Ribeira concentra a maior quantidade de territórios quilombolas, muitos 
deles ainda não reconhecidos ou em processo de reconhecimento, o perímetro da paisagem inclui parte deste conjunto, o que foi possível em função dos estudos já elaborados pelas instituições competentes. A seleção não leva em conta uma diferença de importância ou uma hierarquia de valores existentes, mas ao contrário o princípio da conectividade espacial, tendo em vista o critério central de paisagem linear ou paisagem-corredor.

Nestas áreas ocupadas por populações tradicionais (7) e suas respectivas atividades de subsistência, as quais são suporte físico para o desenvolvimento de diversas manifestações culturais que representam relevante patrimônio imaterial, devem ser garantidas as condições necessárias ao seu exercício, transformação e continuidade no tempo, e de acordo com os seus padrões culturais e suas tradições. Entende-se aqui por tradição o processo histórico pelo qual os elementos da cultura são continuamente reinterpretados e incorporados ao modo de vida, e não como algo que é imutável.

A última grande área a ser conectar ao perímetro da paisagem é o chamado lagamar, adotando-se como limite a APA (Área de Proteção Ambiental) Federal Cananeia-Iguape-Peruíbe. Inclui-se, assim, toda a fachada atlântica sul, onde se desenvolveu importante navegação de cabotagem até o princípio do século 20 , e onde se encontram antigas cidades portuárias, vilas e bairros caiçaras como seus modos de vida peculiares, incontáveis sítios arqueológicos históricos e pré-históricos e o próprio ecossistema estuarino-lagunar, um dos mais significativos de todo o planeta.

Como parte da paisagem da imigração japonesa no Vale do Ribeira foram incluídos, ainda, no perímetro proposto os bens culturais da imigração japonesa, identificados e propostos para tombamento federal no ano de 2008. Trata-se de 14 bens entre edificações fabris, moradias, igrejas e as primeiras mudas de chá trazidas ao Brasil e matrizes de toda a produção nacional, que estão em análise pelo Iphan.

\section{Considerações finais}

Vinte anos se passaram desde que a Constituição Federal inaugurou uma noção renovada de patrimônio cultural, imprimindo novos postulados, os quais já se 
encontravam presentes no debate acadêmico sobre o tema: a superação de uma visão exclusivamente centrada nos "fatos memoráveis" da história oficial nacional; o reconhecimento de uma memória plural, representativa de diversos grupos que compõem a sociedade brasileira; a desvinculação do valor cultural ao caráter excepcional ou monumental dos bens, valor agora identificado nos portadores de referência à ação, memória e identidade dos diversos grupos sociais; a inclusão dos bens intangíveis como uma nova categoria de patrimônio a ser protegida e reconhecida; o entendimento do patrimônio natural como uma natureza incorporada à memória social e parte da vida humana; e, finalmente, a tutela do patrimônio compartilhada entre os poderes públicos e a comunidade.

Entretanto, uma questão se apresenta como fundamental à reflexão: até que ponto este longo percurso de vinte anos resultou em mudanças efetivas nas práticas e na tutela institucional pública? De que forma estes novos postulados constitucionais se refletem nas políticas públicas patrimoniais?

Norteadas por estas duas questões de fundo, o presente artigo procurou apresentar uma experiência de trabalho que vem sendo desenvolvida pelo Iphan, por meio de sua Superintendência em São Paulo, enfatizando que, sem a articulação local e a possibilidade de se entender o patrimônio cultural a partir das lógicas e atribuições locais, pouco se terá avançado.

Mais do que apresentar um trabalho, o presente artigo objetivou, essencialmente, colocar em debate conhecimentos e reflexões produzidas no por meio das práticas institucionais públicas, acreditando que por meio da socialização destas experiências e de sua discussão crítica é que se torna possível construir, coletivamente, as bases sólidas para a tutela patrimonial.

O pacto de construção da chancela consubstanciado no Dossiê da Paisagem Cultural do Vale do Ribeira, só terá pregnância se seus conceitos forem exaustivamente apropriados, reapropriados e discutidos quer em variados âmbitos de interesse e atuação. 


\section{Notas}

(1) Instituto do Patrimônio Histórico e Artístico Nacional, criado em 1937.

(2) Dentre os trabalhos que o Iphan vem desenvolvendo em território nacional, a partir do conceito de paisagem cultural, deve ser citado o estudo pioneiro intitulado "Roteiros Nacionais de Imigração - Santa Catarina". Trata-se de uma ampla pesquisa que mapeou e identificou o patrimônio cultural referenciado em grupos de imigrantes italianos, ucranianos, alemães e poloneses no estado catarinense, os quais contribuíram para a formação do que se chama de "identidade nacional".

(3) Carta de Bagé, artigo $2^{\circ}$ e Portaria IPHAN n ${ }^{\circ} 127$, art. $1^{\circ}$.

(4) Em seu artigo $1^{\circ}$

(5) Orientações para inscrição de tipos específicos de bens na Lista do Patrimônio Mundial, Anexo III do documento Orientações para aplicação da Convenção do patrimônio Mundial, Unesco. Disponível em: $<$ http://whc.unesco.org/>.

(6) Importante esclarecer que o Iphan atua com superintendências regionais, correspondendo aos estados da federação. Neste caso, o trabalho foi proposto e realizado pela Superintendência Regional de São Paulo, circunscrito ao Vale do Ribeira paulista. A expectativa é que seja realizada a expansão do estudo com vias à proteção pela paisagem cultural no Estado do Paraná.

(7) Conforme estabelece o decreto federal $n^{\circ} 6.040 / 2007$ e a lei federal $n^{\circ} 11.428 / 2006$.

\section{Referências bibliográficas}

AB'SÁBER, A. N. Os domínios da natureza no Brasil: potencialidades paisagísticas. São Paulo: Ateliê Editorial, 2003.

BERTRAND, Georges. Paisagem e geografia física global. Caderno Ciências da Terra, n. 13. São Paulo: Universidade de São Paulo/Instituto de Geografia, 1972.

BERTRAND, Georges. Le paysage entre la nature et la societé. Revue Geographique du Pirénées et du Sudoest, Toulouse, tome 49, fasc. 2, p. 239 - 258, 1978.

CAMUS, A. Diário de viagem. Tradução Valeria Rumjanek. 5. ed. São Paulo: Record, 2004.

CONVENÇÃO Européia de Paisagem. Florença, 20/10/2000.

INSTITUTO DO PATRIMÔNIO HISTÓRICO E ARTÍSTICO NACIONAL (IPHAN). Carta de Bagé ou Carta da Paisagem Cultural. Rio Grande de Sul, 18/08/2007.

INSTITUTO DO PATRIMÔNIO HISTÓRICO E ARTÍSTICO NACIONAL (IPHAN). Portaria $n^{\circ} 127$ de 30/04/2009. Estabelece a chancela da Paisagem Cultural Brasileira. 
KRONE, R. Informações ethnographicas do Valle do Rio Ribeira de Iguape. In: COMISSÃO Geographica e Geológica do Estado de São Paulo. Exploração do Rio Ribeira de Iguape. São Paulo: Typographia Brazil, 1914.

PETRONE, Pasquale. A Baixada do Ribeira: estudo de geografia humana. São Paulo: FFLCH/USP, 1966. (Boletim n. 283).

RIBEIRO, R. W. Paisagem cultural e patrimônio. Brasília: Iphan, 2007.

SANTOS, Milton. Por uma geografia nova. São Paulo: Hucitec, 1978.

Pensando o espaço do homem. São Paulo: Edusp, 2004

UNESCO. Orientações para inscrição de tipos específicos de bens na Lista do Patrimônio Mundial. In:. ORIENTAÇÕES para aplicação da Convenção do Patrimônio Mundial, anexo III. Disponível em: <http://whc.unesco.org/>. Acesso em: 17 maio 2005

\section{Créditos}

* Graduada em Arquitetura e História, mestre pela Escola de Engenharia de São Carlos da Universidade de São Paulo (EESC-USP) e doutoranda pela Faculdade de Arquitetura e Urbanismo da Universidade de São Paulo (FAU-USP). Arquiteta e urbanista da Superintendência do Iphan em São Paulo.

e-mail: flaviabn@terra.com.br.

** Graduada em Geografia, mestre e doutora em Geografia pela Faculdade de Filosofia, Letras e Ciências Humanas da Universidade de São Paulo (FFLCH-USP). Docente do Departamento de Geografia da FFLCHUSP.

e-mail: simone.geo@usp.br 